This is the author's version of

Teresa Palomar, Emilio Cano "Comparative assessment of mechanical, chemical and electrochemical procedures for conservation of historical lead" Journal of Cultural Heritage,

Volume 30, 2018, Pages 34-44,

https://doi.org/10.1016/j.culher.2017.10.010. 


\title{
Comparative assessment of mechanical, chemical and electrochemical procedures for conservation of historical lead
}

Teresa Palomar ${ }^{1-2}$, Emilio Cano ${ }^{1}$

${ }^{1}$ Centro Nacional de Investigaciones Metalúrgicas, CENIM-CSIC. Avda. Gregorio del Amo, 8. 28040 Madrid, Spain.

2 Unidade de Investigação VICARTE-Vidro e Cerâmica para as Artes, Campus de Caparica, FCT-UNL, Quinta da Torre, 2829-516 Caparica, Portugal.

\section{E-mail: t.palomar@fct.unl.pt}

\begin{abstract}
Lead has a good resistance to atmospheric corrosion because it forms adherent, uniform and protective layers which prevent the corrosion advancement. Nevertheless, the exposure to the acetic and formic acids -emitted by wood and other materials used in museums' showcases, cabinets and storehouses- induces a corrosion process which can damage the surface of the objects. In order to improve their conservation, restorers apply different conservation treatments which depends on the degree of corrosion, the products formed, the skills of the conservator and the access to specific equipment, if is required.
\end{abstract}

With the aim of evaluating the impact of successive conservation treatments on lead surface and assessing their efficiency, four usual treatments for lead were selected and six cycles of alteration and treatment were carried out. The assessed procedures were mechanical cleaning (suspension of $\mathrm{CaCO}_{3}$ ), chemical cleaning (immersion on EDTA solution) and two electrochemical treatments (potentiostatic reduction, and potentiostatic reduction followed by passivation). The samples were characterized before and after each treatment with gravimetry, colorimetry, rugosimetry, scanning electron microscopy (SEM) and X-ray photoelectron spectroscopy (XPS).

The effects observed on lead coupons depended on each treatment procedure. The mechanical cleaning with $\mathrm{CaCO}_{3}$ produced a significant mass loss and it left an irregular surface due to the granulometry of the abrasive. Additionally, it experienced a fast realteration. Chemical cleaning with EDTA produced moderate mass and gloss losses due to the etching of the metallic surface after successive cycles. However, the color of the samples was the closest to the original one. Finally, the electrochemical reductions 
produced a scarce mass loss and a slow re-alteration, although they produced crystalline deposits on the surface which modified the color of the coupons towards bluish hues.

Keywords: Lead; Alteration; Cleaning methods; Electrochemical reduction; Conservation 


\section{Highlights}

1. Different conservation treatments for degraded historical lead have been evaluated.

2. The most common conservation methods are mechanical treatments, over chemical or electrochemical ones.

3. Mechanical cleaning produced an important mass loss and scratches on the surface

4. Chemical cleaning induced a moderate mass loss and a completely heterogeneous etched surface

5. Electrochemical reduction induced a progressive color change to a bluish hue and a total loss of gloss 


\section{Research aims}

The low hardness of lead makes it particularly susceptible to the damage during the conservation practices; moreover, it requires additional security procedures due to the high toxicity of its corrosion products. The main alterations in the lead surface due to the conservation treatments are the change of color, luminosity, microstructure and chemical composition. The application of successive treatments along several years can intensify these alterations and, therefore, severe and irreversible damages can be produced on lead.

The aim of this study is to evaluate and compare the impact of different procedures for the conservation of historical lead. To achieve this objective, the most commonly used conservation procedures were identified, the effects on the lead surface after successive treatments were characterized, and the stability of the treatments was assessed.

\section{Introduction}

Lead is the most common heavy metal in the Earth crust. It presents a bluish-gray color, is very soft and has high density [1, 2]. Historically, lead is one of the earlier used metals, lead rivets were used to mend pottery since 3000 B.C. in the Middle East [3]. Its low melting point and high workability favored the production of several objects such as coffins, funeral urns, epigraphic sheets, seals, medals, plummets, sinkers, military objects, soldier toys, printing types, organ tubes and other decorative and utilitarian items. In addition, lead has been used in objects with urban and structural function such as water pipes, roofing and lead cames for stained glass windows [1].

Lead has good resistance to atmospheric corrosion because it reacts with environmental oxygen to form a passive layer of lead oxide ( $\mathrm{PbO})$ (Reaction 1) [4].

$\mathrm{Pb}+1 / 2 \mathrm{O}_{2} \rightarrow \alpha-\mathrm{PbO}$

The $\mathrm{CO}_{2}$ dissolved in the rain and the condensation water can react with the oxides to form carbonates such as the plumbonacrite $\left(6 \mathrm{PbCO}_{3} \cdot 3 \mathrm{~Pb}(\mathrm{OH})_{2} \cdot \mathrm{PbO}\right)$ (Reaction 2) which form an adherent, uniform and protective layer [5].

$10 \mathrm{PbO}+6 \mathrm{CO}_{2}+3 \mathrm{H}_{2} \mathrm{O} \rightarrow 6 \mathrm{PbCO}_{3} \cdot 3 \mathrm{~Pb}(\mathrm{OH})_{2} \cdot \mathrm{PbO}$

However, some volatile organic compounds (VOCs) can break the protective layer and trigger the degradation process. The main alteration agent is the acetic acid which, dissolved in the condensation water, can react with the protective passive layer to form hydrated lead acetate (Reaction 3). 
$\mathrm{PbO}+2 \mathrm{CH}_{3} \mathrm{CO}_{2} \mathrm{H} \rightarrow \mathrm{Pb}\left(\mathrm{CH}_{3} \mathrm{CO}_{2}\right)_{2}+\mathrm{H}_{2} \mathrm{O}$

Lead acetate acts as a catalyst because favors the transformation of environmental $\mathrm{CO}_{2}$ to lead carbonates. The result is the formation of a whitish, powdery and low-adhesion alteration layer on the lead surface. The reactivity of acetate has a direct relationship with the environmental humidity, mainly at relative humidity above $67 \%$ [5-7], and the species most common formed are plumbonacrite, hydrocerussite $\left(2 \mathrm{PbCO}_{3} \cdot \mathrm{Pb}(\mathrm{OH})_{2}\right)$ and cerussite $\left(\mathrm{PbCO}_{3}\right)$ (Reactions 4, 5, 6 and 7), although plumbonacrite is the most favored one because it is the most stable compound in the system $\mathrm{PbO}-\mathrm{CO}_{2}-\mathrm{H}_{2} \mathrm{O}[5,8]$.

$$
\begin{aligned}
& 10 \mathrm{~Pb}\left(\mathrm{CH}_{3} \mathrm{CO}_{2}\right)_{2}+13 \mathrm{H}_{2} \mathrm{O}+6 \mathrm{CO}_{2} \rightarrow 6 \mathrm{PbCO}_{3} \cdot 3 \mathrm{~Pb}(\mathrm{OH})_{2} \cdot \mathrm{PbO}+20 \mathrm{CH}_{3} \mathrm{CO}_{2} \mathrm{H} \\
& 3 \mathrm{~Pb}\left(\mathrm{CH}_{3} \mathrm{CO}_{2}\right)_{2}+4 \mathrm{H}_{2} \mathrm{O}+2 \mathrm{CO}_{2} \rightarrow 2 \mathrm{PbCO}_{3} \cdot \mathrm{Pb}(\mathrm{OH})_{2}+6 \mathrm{CH}_{3} \mathrm{CO}_{2} \mathrm{H} \\
& 3\left[6 \mathrm{PbCO}_{3} \cdot 3 \mathrm{~Pb}(\mathrm{OH})_{2} \cdot \mathrm{PbO}\right]+2 \mathrm{CO}_{2}+\mathrm{H}_{2} \mathrm{O} \rightarrow 10\left[2 \mathrm{PbCO}_{3} \cdot \mathrm{Pb}(\mathrm{OH})_{2}\right] \\
& 2 \mathrm{PbCO}_{3} \cdot \mathrm{Pb}(\mathrm{OH})_{2}+\mathrm{CO}_{2} \rightarrow 3 \mathrm{PbCO}_{3}+\mathrm{H}_{2} \mathrm{O}
\end{aligned}
$$

Contrary to the plumbonacrite formed from lead oxides upon atmospheric exposure (Reaction 2), this layer is poorly adherent and does not protect the metallic surface from further corrosion. Furthermore, formation of carbonates according to reactions 4 and 5 release the acetic acid which further reacts with the unaltered metal. The formic acid also catalyzes the corrosion of lead, although to a lesser extent than acetic acid because the lead formate $\left(\mathrm{Pb}\left(\mathrm{CHO}_{2}\right)_{2}\right)$ is less soluble than acetate and, therefore, the corrosion layer is more stable (Reaction 8) [9, 10].

$\mathrm{PbO}+2 \mathrm{HCO}_{2} \mathrm{H} \rightarrow \mathrm{Pb}\left(\mathrm{CHO}_{2}\right)_{2}+\mathrm{H}_{2} \mathrm{O}$

The principal risk to the heritage of lead in museums is the accumulation of the VOCs inside the cabinets, showcases and storehouses, whose concentration could be up to 20 times higher than inside the museum [6]. These VOCs are emitted by the building materials of the museum enclosures, such as natural woods, silicones, paints and varnishes [1, 11-14]. This attack has also been registered in historical organ pipes due to the alteration of the wood from the wind system $[4,10,15,16]$ and in the lower side of lead roofs due to the alteration of the wooden roof supports [17].

Those objects with a severe state of corrosion require a conservation treatment to restore its legibility and its conservation state. Historically, the most commonly used procedures were the mechanical treatments with abrasives, scalpels or fiberglass brushes, although the low hardness of lead makes it particularly susceptible to be damaged during the cleaning $[2,18,19]$. Lead has a hardness of 1.5 on the Mohs scale, lower than its most 
common corrosion products such as $\mathrm{PbO}$ (2.0), $\mathrm{PbCO}_{3}$ (3.3) or $\mathrm{PbSO}_{4}$ (2.8) [20]. Among the most usual abrasives, $\mathrm{CaCO}_{3}$ has a hardness of 3 , similar to the corrosion products of lead. Abrasives with higher hardness such as $\mathrm{TiO}_{2}$ (5-5.6), $\mathrm{SiO}_{2}$ (7) or $\mathrm{Al}_{2} \mathrm{O}_{3}$ (9) could produce several damage on the objects, while abrasive with lower hardness such as kaolinite (2-2.5) or talc (1) could not clean the corrosion products on the surface [21].

The most commonly applied chemical treatments were acids and bases, which can remove thick corrosion crusts [2, 19]. The Caley method is the most renowned, consisting in the cleaning with an aqueous solution of $\mathrm{HCl}(1: 10)$ followed by the treatment with $\mathrm{CH}_{3} \mathrm{COONH}_{4}$ to remove the $\mathrm{PbO}_{2}$ and neutralize the acidity $[19,22]$. The problem of this method is the amphoteric nature of lead. The objects can be severe damaged if the $\mathrm{pH}$ was not controlled or the remains of the solutions were not well cleaned. Chelating agents, as ethylenediamine tetraacetic acid (EDTA), have also been applied for the chemical cleaning of complex corrosion crusts because it dissolves most of the species of lead, instead of $\mathrm{PbO}[19,23,24]$. In case of ion exchange resins, they are useful to clean carbonates because the resin absorbs the lead ions and releases water soluble compounds to media [2].

Electrochemical procedures have also been applied for the conservation of historical lead. This treatments allow the electrochemical reduction of the corrosion products to consolidate the lead objects minimizing the mass loss [25]. The galvanic reduction (normally named "electrochemical reduction" in conservation literature) has been widely applied. In this procedure, the object to be treated and a less-noble metal, usually zinc or aluminum, are kept in contact in a conducting solution. The main inconvenient of this procedure is the lack of selectivity and control of the reactions that takes place [2, 26]. The reduction treatment can also be applied with an external power source, known in the conservation literature as "electrolytic reduction", both under current (galvanostatic treatments) or potential (potentiostatic treatments) control. The galvanostatic treatment maintains stable the current which permits to treat different objects simultaneously; although water dissociation can easily occur and objects can be damaged by hydrogen evolution [27] .A refinement of this procedure, known as "consolidative reduction", involves the use of low currents to hinder hydrogen evolution and effectively reduce the corrosion products back to the metal, but it is a slow process and the formation of hydrogen is not completely avoided [28, 29]. The potentiostatic treatment controls the potential applied to the object; it is possible to discriminate between different reactions and to control them, so only the desired ones take place [28, 30]. The most common electrolytes to treat lead are aqueous solutions of $\mathrm{NaOH}, \mathrm{Na}_{2} \mathrm{CO}_{3}, \mathrm{H}_{2} \mathrm{SO}_{4}$ and $\mathrm{Na}_{2} \mathrm{SO}_{4}$, 
although the $\mathrm{Na}_{2} \mathrm{SO}_{4}$ seems to be the safest solution both for metal and for its corrosion protucts [29].

Given the importance of the preservation of cultural heritage in lead, it is essential to know the impact of the conservation procedures on it. Several works have proved that treatments produce chemical and morphological changes in the lead surface, which can be unperceived by conservators. Adams [24] carried out a comparative study on the effect of three chelating agents (ethylenediamine tetraacetic acid, EDTA; diethylenetriamine pentaacetic acid, DTPA; and sodium triphosphate, STP) on lead coupons and demonstrated that the DTPA was the most effective chelating agent for lead carbonate, the EDTA induced the distortion of the surface, and the STP acted too slow and the chelated products precipitated on the metal. Schotte et al. [31] proved that the reduction of the corrosion products of lead could stabilize the corroded metal, although the morphology of the regenerated corrosion structures changed increasing their specific area and favoring the re-oxidation.

Ideally, after conservation-restoration treatments, objects should not be re-exposed to the aggressive environment. However, this is not always the case: changes in the museography, rearrangement of exhibitions or storage areas, temporary exhibitions or loans may in some cases expose again the object to less-than-ideal conditions, resulting in new corrosion cycles, which in turn will require a new treatment [28]. Considering the (ideally) indefinite lifespan of the heritage objects, these corrosion/conservation cycles will accumulate over the decades or centuries. The effects on the lead surface due to the conservation procedures can become worse with the repetitive treatments. However, the information about these impacts is scarce. For this reason, the principal objective of this study was the evaluation and comparison of common conservation procedures on lead coupons to identify the main alterations in lead surface (color, luminosity, morphology, chemical composition) and the impact of these procedures (mass loss and cleaning efficiency) after successive cycles of alteration and conservation treatment.

The selection of conservation procedures was carried out by means of a survey conducted to worldwide conservators. In the survey, conservators detailed the conservation procedures and their personal experience with them. The survey had 36 answers. According to the answers, the most commonly applied methods were mechanical treatments (46\%), over chemical (32\%) or electrochemical (16\%) (Fig. 1 a). The less popular methods were laser and plasma procedures. 


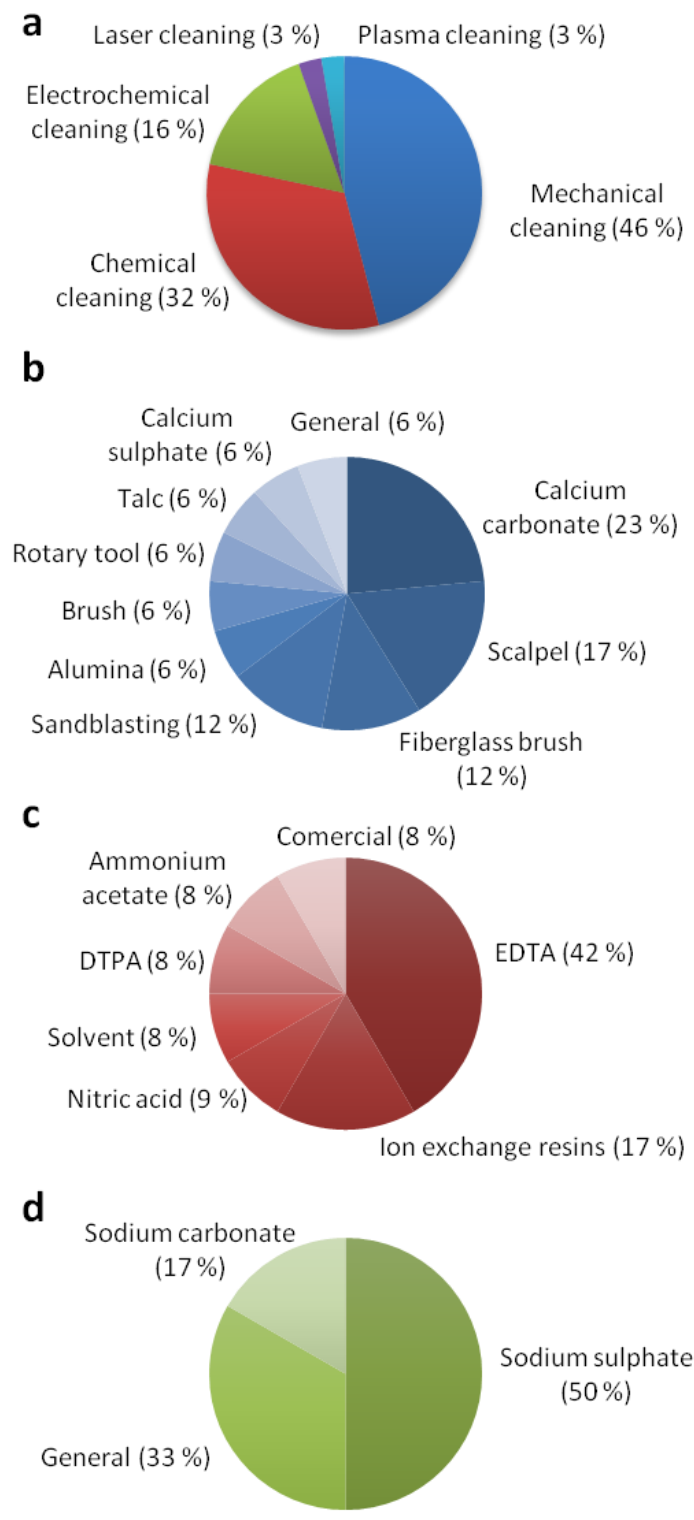

Fig. 1. a) Nature of the treatments; and detail of the procedures of b) mechanical cleaning, c) chemical cleaning, d) electrochemical reductions, according to the results of the survey.

The most common mechanical cleanings are the abrasion with a suspension of calcium carbonate in water or ethanol (23\%), and cleaning with scalpels (17\%) and fiberglass brushes (12\%) (Fig. $1 \mathrm{~b}$ ). Conservators indicated that these treatments presented a moderate-good cleaning efficiency. The final aspect of the surface could not be uniform, although in the majority of the cases they were considered optimum. The sandblasting has been applied mainly in the lead cames of stained glass windows because it permits a fast cleaning in a big surface. Nevertheless, if the cleaning is too aggressive, it can produce a serious structural risk. Other mechanical procedures less in use are the cleaning with suspensions of aluminum or calcium sulphate, with brush or with a rotary tool (Fig. 1 b). 
In the chemical cleanings, liquid reagents were normally applied with swabs, poultices or by immersion. According to the conservators, the most common reagent was the chelating agent EDTA (42\%, Fig. $1 \mathrm{c}$ ) because it has an easy methodology, the cleaning speed is intermediate and the final aspect is considered by conservators to be optimum. Moreover, according to conservators, this technique is specially indicated to objects of small size. The ion exchange resin $(17 \%)$ produces an optimum result but, in comparison with the EDTA, the cleaning speed is slower. Other chemical reagents less in use are nitric acid, the chelating agent DTPA, ammonium acetate and commercial products (Fig. $1 \mathrm{c})$.

The electrochemical reduction procedure most applied was the method defined by Degrigny and Le Gall [29], based on the electrolytic reduction in sodium sulphate electrolyte (Fig. 1 d). According to the results of the survey, the final aspect of lead is optimum and it allows to treat several objects simultaneously, although it requires to have advanced equipment and knowledge to avoid an incorrect manipulation and to minimize the damage to the historical object.

Given the results of the survey, the conservation treatments chosen for this study were the surface abrasion with a suspension of $\mathrm{CaCO}_{3}$ in ethanol, the chemical cleaning with an aqueous solution of EDTA and the potentiostatic reduction of the corrosion products in an aqueous solution of $\mathrm{Na}_{2} \mathrm{SO}_{4}$. Additionally, the potentiostatic reduction and passivation in an aqueous solution of $\mathrm{Na}_{2} \mathrm{SO}_{4}$ was also evaluated.

\section{Material and methods}

\subsection{Samples}

The evaluation of conservation methods was carried out on coupons of pure lead (3.0 $\mathrm{x}$ $3.0 \times 0.2 \mathrm{~cm}$ ). Their surface composition was analyzed by wavelength dispersive X-ray fluorescence (WDXRF) with a Bruker S8 Tiger system. They presented 92.50 wt. \% of lead, $6.23 \mathrm{wt}$. \% of oxygen, $0.37 \mathrm{wt}$. \% of silicon, $0.22 \mathrm{wt}$ \% of zirconium, $0.21 \mathrm{wt}$ \% of sodium, 0.14 wt. $\%$ of chloride, 0.13 wt. \% of calcium, 0.12 wt. \% of aluminum, 0.06 wt. $\%$ of potassium, 0.01 wt. \% of rubidium and 0.01 wt. \% of sulphur. The coupons were abraded with emery paper, down to grade 2000 under water jet and washed with distilled water in an ultrasonic bath for two minutes.

\subsection{Lead alteration}

Alteration was carried out by exposure the lead coupons to an atmosphere polluted with 10 ppm of acetic acid [9]. The time of exposure was chosen by the previous evaluation 
of the changes in mass, color and gloss during ten days. The degree of the alteration chosen for this study was the representative of an advanced alteration level that can be found in real objects, and it was obtained after four days of exposure. From the fifth day of exposure, the visual aspect of the tarnished coupon (color and gloss) changed slowly.

The X-ray diffraction of the tarnished coupon showed the presence of metallic lead, related with the metallic nucleus of the coupon, as well as lead oxide (I), litharge and massicot $\left(\mathrm{Pb}_{2} \mathrm{O}, \alpha-\mathrm{PbO}\right.$ and $\beta-\mathrm{PbO}$, respectively), hydrated lead oxide $\left(\mathrm{PbO} \cdot 4 \mathrm{H}_{2} \mathrm{O}\right)$ and the carbonates cerussite, hydrocerussite and plumbonacrite (Fig. 2 a and b).
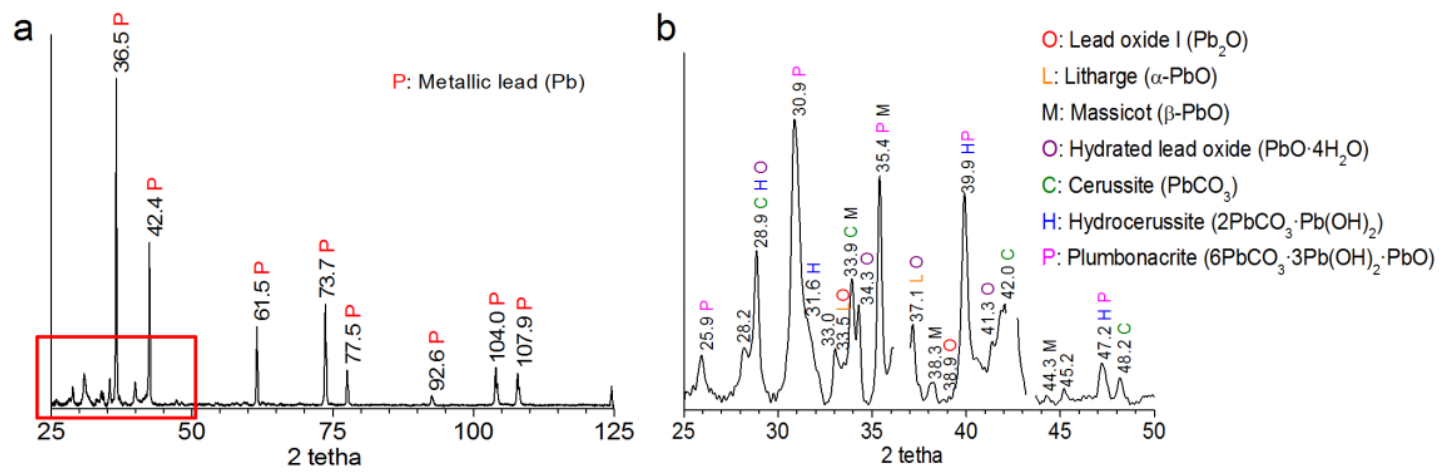

Fig. 2. Diffractogram of the corrosion layer of the tarnished lead a) between $25-125^{\circ}$, and b) between $25-50^{\circ}$ without the peaks of the metallic lead (scaling up the red square in the Fig. 2 a).

\subsection{Treatments}

Coupons were subjected to six cycles of induced alteration and conservation treatment to assess the cumulative effects of the repetitive treatments that will be applied over decades to lead heritage artifacts. The conservation treatments were selected according to the survey. The chosen procedures are summarized in Table 1.

Table 1. Summary of conservation procedures evaluated

\begin{tabular}{ll}
\hline Abbreviations & Conservation treatment description \\
\hline MC & Mechanical cleaning with a suspension of $\mathrm{CaCO}_{3}$ in ethanol \\
$\mathrm{CE}$ & Chemical cleaning with an aqueous solution of EDTA $5 \% \mathrm{w} / \mathrm{w}(30 \mathrm{~s})$ \\
$\mathrm{ES}$ & Electrochemical reduction under potentiostatic control $\left(-900 \mathrm{mV} \mathrm{Ag}_{\mathrm{AgCl}}, 400\right.$ \\
$\mathrm{EP}$ & s) in an aqueous solution of $\mathrm{Na}_{2} \mathrm{SO}_{4} 5 \% \mathrm{w} / \mathrm{w}$ \\
& $\begin{array}{l}\text { Electrochemical reduction under potentiostatic control }\left(-900 \mathrm{mV} \mathrm{Ag}_{\mathrm{AgCl}}, 400\right. \\
\text { s) and subsequent passivation }\left(-300 \mathrm{mV}_{\mathrm{Ag}-\mathrm{AgCl}}, 300 \mathrm{~s}\right) \text { in an aqueous }\end{array}$ \\
& solution of $\mathrm{Na}_{2} \mathrm{SO}_{4} 5 \% \mathrm{w} / \mathrm{w}$ \\
\hline
\end{tabular}

The mechanical cleaning (MC) was applied by surface abrasion with a suspension of $\mathrm{CaCO}_{3}$ in ethanol $\left(\mathrm{CH}_{3} \mathrm{CH}_{2} \mathrm{OH}\right)$ carried out by a professional metal conservator; the chemical cleaning (CE) was carried out by immersion for $30 \mathrm{~s}$ in an aqueous solution of EDTA $\left(\mathrm{C}_{10} \mathrm{H}_{16} \mathrm{~N}_{2} \mathrm{O}_{8}\right) 5 \% \mathrm{w} / \mathrm{w}$; the electrochemical reductions were carried out with a Gamry Ref. 600, using an aqueous solution of $\mathrm{Na}_{2} \mathrm{SO}_{4}(5 \% \mathrm{w} / \mathrm{w})$ as electrolyte, and a 
$\mathrm{Ag} / \mathrm{AgCl}$ reference electrode. To choose the reduction and passivation potential, two potentiodynamic (linear sweep voltammogram) curves of tarnished coupons were carried out with a potential scan rate of $1 \mathrm{mV} / \mathrm{s}$. The reduction peak potential appeared in the cathodic scan at $-775 \mathrm{mV}_{\mathrm{Ag} / \mathrm{AgCl}}$ and the passivation peak in the anodic scan at $409 \mathrm{mV}_{\mathrm{Ag} / \mathrm{AgCl}}$. Electrochemical treatment by potentiostatic reduction (ES) was carried out at $-900 \mathrm{mV} \mathrm{Ag}_{\mathrm{AgCl}}$ for $400 \mathrm{~s}$, to assure the complete reduction of corrosion products, while avoiding hydrogen evolution. Electrochemical treatment followed by passivation (EP) was carried out using the same potentiostatic reduction conditions, followed by a potentiostatic passivation at $-300 \mathrm{mV}_{\mathrm{Ag} / \mathrm{AgCl}}$ for $300 \mathrm{~s}$ to form a layer of $\mathrm{PbSO}_{4}$ on the surface of the coupons.

\subsection{Characterization techniques}

The samples were characterized before and after each treatment by different techniques such as gravimetry, colorimetry, rugosimetry, scanning electron microscopy (SEM) and X-ray photoelectron spectroscopy (XPS). X-ray diffraction (XRD) was applied to identify the corrosion products formed during the alteration in the acetic acid atmosphere (section $3.2)$.

The mass variation was evaluated using a Mettler Toledo AT261 Delta Range Analytical Balance. Lead coupons were weighed after each treatment to determine the mass loss(Eq. 9).

$$
\Delta \text { mass }=\text { mass treated lead }- \text { mass } \text { original lead }
$$

To evaluate the re-alteration effect, the average mass increase after the alteration cycles was calculated by weighting the coupon before and after each alteration (Eq. 10):

Average mass increase $=\frac{\left.\sum \text { (mass tarnished lead }- \text { mass treated lead }\right)}{\text { number of cycles }}$

A Konica Minolta Portable spectrophotometer model 2500D equipped with a mask of 8 $\mathrm{mm}$ of diameter, D65 illuminant (which corresponds to the average noon daylight from the northern sky [32]) and at $10^{\circ}$ observer, served to measure the chromatic properties of the samples and specifically the changes induced by the conservation procedures. Two spectra were acquired on each side of the coupon and averaged to obtain one data point with the chromatic information. Results were expressed using the CIE-L* $a^{*} b^{*}$ color space with Specular Component Include (SCI). The chromatic coordinates $\mathrm{a}^{*}$ and $\mathrm{b}^{*}$ denote the red/green value (positive values shift to red, negative values shift to green), and the yellow/blue value (positive values shift to yellow, negative values shift to blue) respectively $[33,34]$. The chromaticity change after each alteration-treatment cycle was 
represented by $a^{*}$ vs. $b^{*}$. The gloss variation between the original lead and after each cycle of treatment, $\Delta$ gloss, was evaluated by:

$$
\Delta \text { gloss }=\text { gloss } \text { treated lead }- \text { gloss original lead }
$$

On the other hand, the re-alteration effect was evaluated by the change of lightness value after each alteration cycle:

$$
\Delta \mathrm{L}^{*}=\mid \mathrm{L}^{*} \text { tarnished lead }-\mathrm{L}^{*} \text { treated lead } \mid
$$

Surface rugosimetry was quantified with an optic rugosimeter TRACEiT from Innowep $\mathrm{GmbH}$. The topographical maps in 3D $(5 \times 5 \mathrm{~mm})$ had a resolution of $2.5 \mu \mathrm{m}$ ( $Z$ axis $)$ and $2.5 \mu \mathrm{m}(\mathrm{X} / \mathrm{Y}$ axis).

Scanning electron micrographs (SEM) were obtained using the secondary electrons detector of a Hitachi S-4800 microscope, equipped with a cold-cathode field emission electron gun and an Oxford INCA system for energy dispersive X-ray spectrometry microanalysis (EDX).

The chemical composition of the surface was analyzed by X-ray photoelectron spectroscopy (XPS). XPS spectra were recorded using a Fisons MT500 spectrometer fitted with a hemispherical electron analyzer (CLAM2) and a non-monochromatic Mg Ka X-Ray source operated at $300 \mathrm{~W}(1253.6 \mathrm{eV})$. The samples were fixed on small flat discs supported on an XYZ manipulator placed in the analysis chamber. The residual pressure in this ion-pumped analysis chamber was maintained below $10^{-9}$ Torr during data acquisition. The spectra were recorded at take-off angles of $90^{\circ}$ and pass energy of 20 $\mathrm{eV}$, which is typical of high-resolution conditions. The intensities were estimated by calculating the area under each peak after subtraction of the S-shaped background and fitting the experimental curve to a combination of Lorentzian and Gaussian fits of variable proportions. Although specimen charging was observed, it was possible to determine accurate binding energies (BE) by referencing to the adventitious $C$ 1s peak at $285.0 \mathrm{eV}$ with accuracy to $\pm 0.2 \mathrm{eV}$. The atomic ratios were computed from the peak intensity ratios and the reported atomic sensitivity factors [35]. The peaks assignation was carried out using the database of the National Institute of Standards and Technology (NIST) [36].

XRD measurements were performed with a Bruker AXS D8 diffractometer equipped with a cobalt X-ray tube, Goebel mirror optics. A current of $30 \mathrm{~mA}$ and a voltage of $40 \mathrm{kV}$ were employed as tube settings. The XRD data was collected over a $2 \theta$ range of $25-120^{\circ}$ with a step size of $0.03^{\circ}$ and an acquisition step time of $3 \mathrm{~s}$. The qualitative identification of 
crystalline phases was performed from XRD patterns using the Match! Version 2.1.2 software and the database PDF-2 Release 2004.

\section{Results and discussion}

\subsection{Gravimetry}

In ideal circumstances, the conservation treatment of historical objects should only remove the alteration without mass loss from the base metal. However, all treatments produced a progressive mass depletion on the coupons (Fig. 3). Mechanical cleaning is the most aggressive procedure because it induced the highest loss of material by removal of an average over $0.6 \mathrm{mg} / \mathrm{cm}^{2}$ in each cleaning cycle (Fig. 3). The nonhomogeneous mass loss produced by the mechanical treatment was due to the subjective finish of the treatment which depended on the conservator. In addition, the polishing left an extremely active surface. It was observed an increase of $\sim 0.07 \mathrm{mg} / \mathrm{cm}^{2}$ after each alteration exposure (Table 2), which is attributable to the additional mass of new corrosion products formed on the surface. This method produced the largest mass increase -i.e., the fastest corrosion rate- after cleaning, indicating that the freshly exposed metallic surface is highly reactive, and therefore very prone to subsequent degradation.

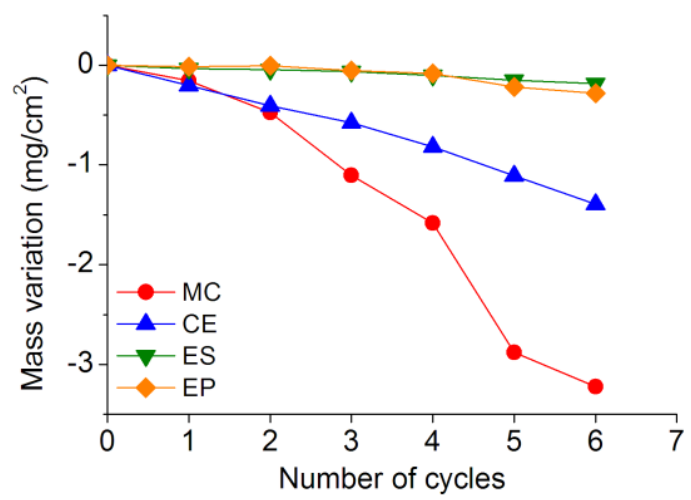

Fig. 3. Mass variation as a function of the number of alteration-treatment cycles (Eq. 9).

Table 2. Average mass increase after each alteration exposure for the different conservation procedures (Eq. 10).

\begin{tabular}{ll}
\hline & \\
\hline MC & 0.07 \\
CE & 0.04 \\
ES & 0.03 \\
EP & 0.03 \\
\hline
\end{tabular}

Chemical cleaning with EDTA produced a constant mass loss of $\sim 0.3 \mathrm{mg} / \mathrm{cm}^{2}$ after each alteration-cleaning cycle, approximately the half of the mechanical cleaning (Fig. 3). 
Nevertheless, after six successive alteration-cleaning cycles, there was an appreciable loss $\left(\sim 1.5 \mathrm{mg} / \mathrm{cm}^{2}\right)$.

On the contrary, electrochemical methods were the less aggressive treatments from the point of view of mass loss, since they showed an almost constant mass after the whole six cycles (Fig. 3) because corrosion products were reduced to metallic lead with a minimum loss of material. Furthermore, the surface showed the lowest reactivity (Table 2).

\subsection{Rugosimetry}

All treatments induced a modification of the original lead surface as a consequence of the six successive alteration-treatment cycles.

The original lead coupon presented the most homogeneous surface (Fig. $4 P_{0}$ ), nevertheless the alteration produced globular deposits on the surface (Fig. $4 \mathrm{P}_{1}$ ). 

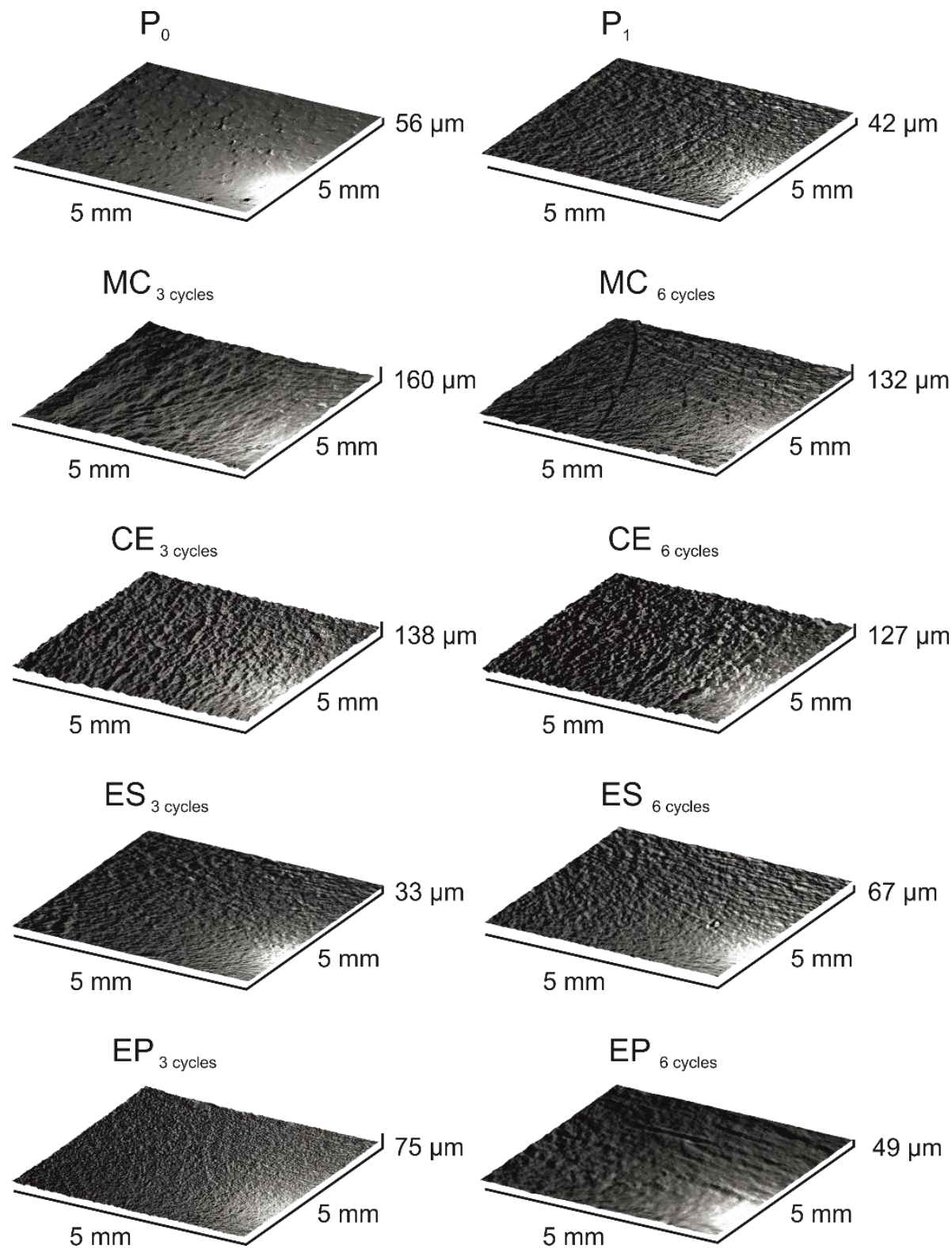

$49 \mu \mathrm{m}$

Fig. 4. Rugosimetry images $(5 \times 5 \mathrm{~mm})$ of the surface of original $\left(\mathrm{P}_{0}\right)$ and tarnished $\left(\mathrm{P}_{1}\right)$ coupons, and the surface after the third and the sixth alteration-treatment cycles.

The roughness of lead surface after the alteration-treatment cycles depended on the procedures. The surface of the coupons cleaned mechanically was irregular due to the abrasive which left scratches on the surface (Fig. $4 \mathrm{MC}$ ). The coupons chemically cleaned presented a heterogeneous surface because the reaction of lead with EDTA etched the surface enlarging the original scratches (Fig. $4 \mathrm{CE}$ ). The roughness after three and six cycles was similar to each other because the chemical treatment modified the surface during the first cycles and, afterwards, the irregularity was almost constant.

The electrochemical procedures presented two different behaviors. The potentiostatic reductions produced microcrystals of lead which preserved the morphology of the corrosion products. The roughness increased in each cycle of alteration and reduction, because new corrosion products were formed on the reduced microcrystals of lead (Fig. 
4 ES). Nevertheless, the potentiostatic reduction and passivation formed crystals of $\mathrm{Pb}^{0}$ and $\mathrm{PbSO}_{4}$, which were grown in the cavities favoring the flattening of the surface (Fig. 4 EP).

\subsection{Scanning electron microscopy}

The original surface of the coupons presented a smooth surface with scratches due to the sample preparation (Fig. 5 a). However, the exposure during four days in an acetic acid atmosphere formed several corrosion products with globular morphology (Fig. $5 \mathrm{~b}$ and c). These deposits are similar to those ones observed in other studies $[4,10]$.
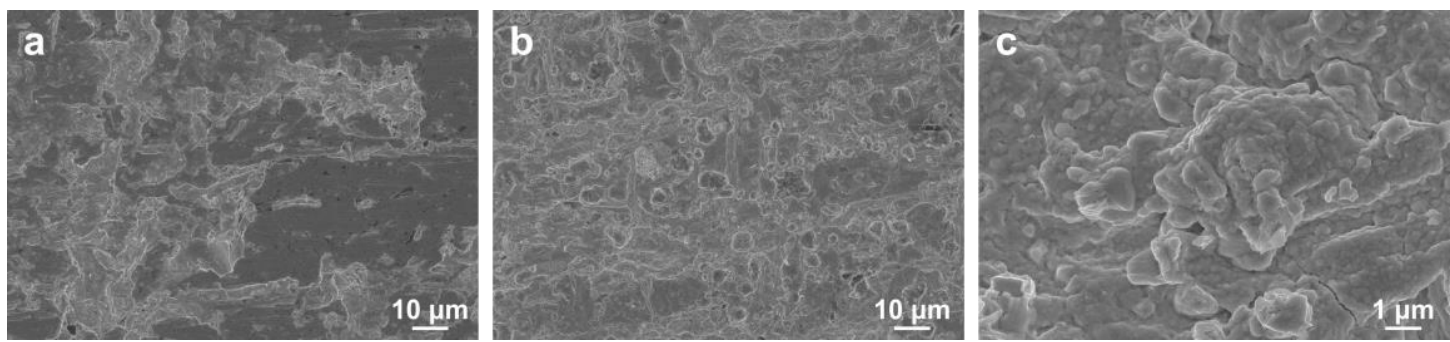

Fig. 5. SEM images of the a) original coupons; b, c) tarnished coupons.

The lead coupons mechanically cleaned presented an irregular surface due to the grain size of the abrasive (Fig. $4 \mathrm{MC}$ ), nevertheless the surface microstructure was almost smooth, although in some areas, where the abrasion was less intense, appeared some of the original scratches (Fig. 6 a). The manual character of the cleaning was also observed in the non-homogeneous mass loss (section 4.1.). 

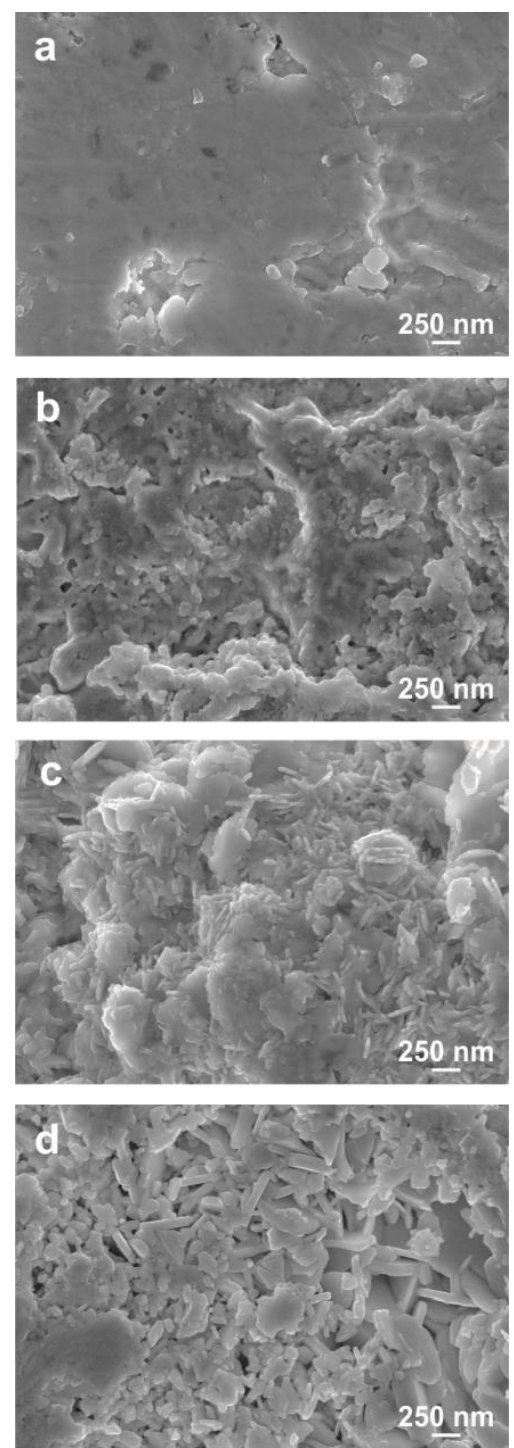

Fig. 6. SEM images of the coupons treated a) with $\mathrm{CaCO}_{3}(\mathrm{MC})$, b) with $\mathrm{EDTA}(\mathrm{CE})$, c) by potentiostatic reduction $(E S), d$ ) by potentiostatic reduction and passivation (EP).

The chemical cleaning by immersion in EDTA induced a very heterogeneous surface on lead (Fig. 6 b). The original scratches were widened and deepened, creating lots of pits which could retain the cleaning solution. This alteration on lead due to EDTA has been observed previously [24].

The cycles of alteration and potentiostatic reduction induced a rough surface on the lead coupon. The electrochemical reduction favored the re-crystallization of the corrosion products (lamellae structures) although they preserved the original globular morphology (Fig. 6 c). After successive alteration and treatments, complex microstructures were formed. A similar behavior has been observed in the electrochemical reduction of silver [37].

Finally, the cycles of alteration and potentiostatic reduction and passivation favored the formation of two different crystalline deposits which could be related with metallic lead 
and $\mathrm{PbSO}_{4}$ (Fig. 6 d). The growth of these crystals in the cavities favored the diminishing of the roughness.

\subsection{Colorimetry}

The color of the metallic surface is an important factor in conservation science, because the objective of the conservation procedure is the recuperation of the original appearance of the object. Nevertheless, all the treatments induced a color change in the lead coupons (Fig. 7). The chromatic variation in the coupons cleaned mechanically (MC) and chemically $(\mathrm{CE})$ was low because the abrasive and the chelating agent removed the corrosion layer of the coupon exposing a fresh metallic lead surface. They presented a color between the original and the tarnished coupon $\left(\Delta a^{*}<0\right)$ (Fig. 7). On the contrary, electrochemical procedures (ES, EP) progressively modified the color of the lead towards a bluish color $\left(\Delta a^{*}, \Delta b^{*}<0\right)$ caused by the re-crystallization of the corrosion products on the coupons.

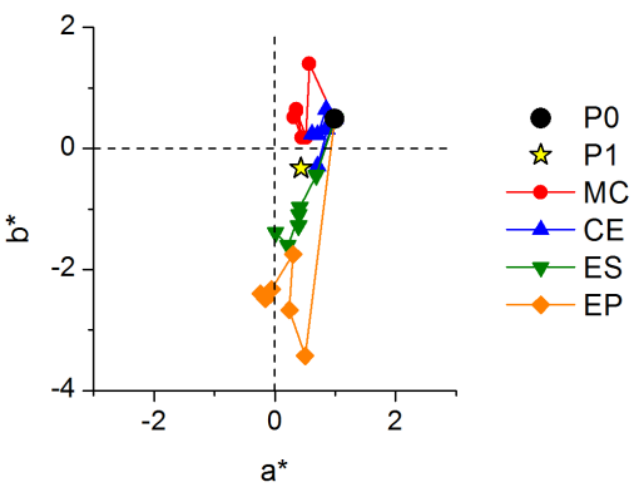

Fig. 7. Chromatic variation $a^{*}$ vs. $b^{*}$ of the lead coupons in function of the number of alteration-treatment cycles.

The formation of new crystals by electrochemical procedures also diminished the gloss of the coupons because they modified the roughness of the lead surface (Fig. 8 a). However, mechanical and chemical cleanings increased the gloss because they revealed the metallic nucleus of lead (Fig. 8 a).
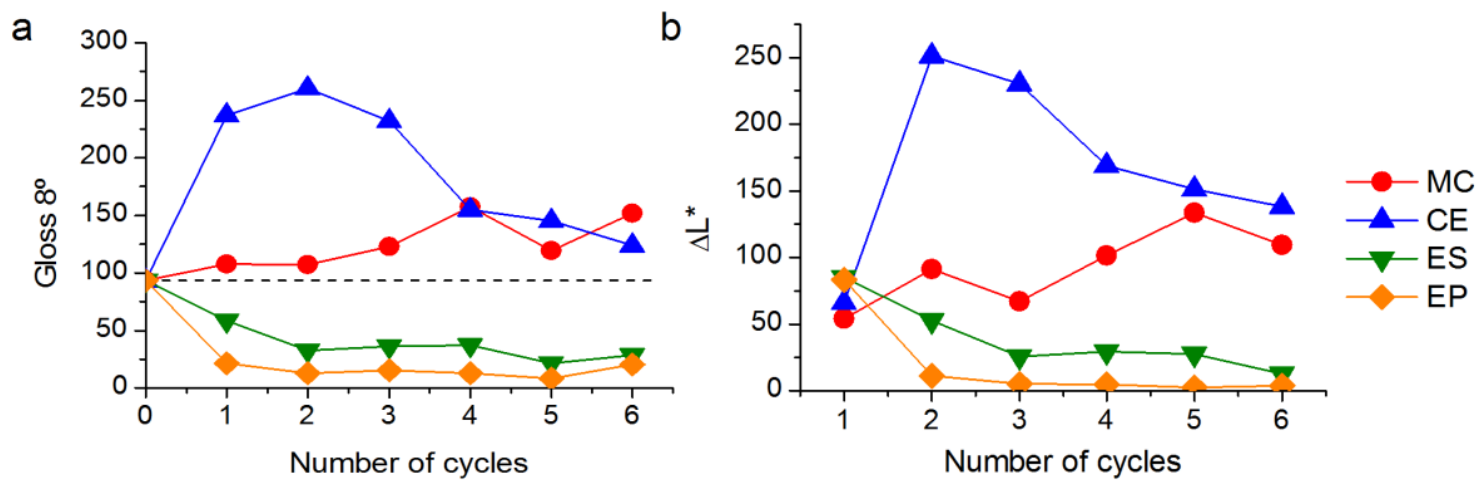
Fig. 8. a) Gloss variation (Eq. 11), and b) luminosity variation $\left(\Delta L^{*}\right.$, Eq. 12), in function of the number of alteration-treatment cycles. The grey dashed line showed the gloss of the original coupon.

The variation of luminosity during the alteration $\left(\Delta \mathrm{L}^{*}\right)$ served to evaluate the re-alteration rate, because after repetitive alteration-treatments cycles the acetic acid reacted differently with the lead coupons. Chemical cleaning left the most activated surface by visual perception in the first cycles because the treatment revealed the metallic lead on the surface which reacted quickly to acetic acid (Fig. 8 b). It was observed also a progressive decrease of the re-alteration after de second cycle because the EDTA solution diminished the luminosity and gloss of the cleaned lead surface (Fig. 8 a), which can be related with the increase of the roughness by the chemical etching of the surface, as shown in Figs. 4 and 6 . The luminosity variation in the coupons treated by successive cycles of alteration and potentiostatic reduction and passivation was negligible (Fig. 8 b), because of the formation of $\mathrm{PbSO}_{4}$ layer which acted as a corrosion barrier. Even the visual change of the alteration in the coupons treated by potentiostatic reduction showed a low change due to the decrease of the luminosity of the surface. The re-alteration in the coupons mechanically cleaned experienced a progressively increase, related with the increase of the luminosity and gloss (Fig. $8 \mathrm{a}$ ).

\subsection{X-ray photoelectron spectroscopy}

The chemical state and the electronic structure of the elements in the surface of the lead coupons were characterized by XPS.

XPS spectra of lead coupons showed the presence of carbon, oxygen and lead; additionally calcium, nitrogen, sulfur and sodium, related with the remains of the cleaning products, were identified in the treated coupons. 


\section{a) $\mathrm{Pb} 4 \mathrm{f}$}

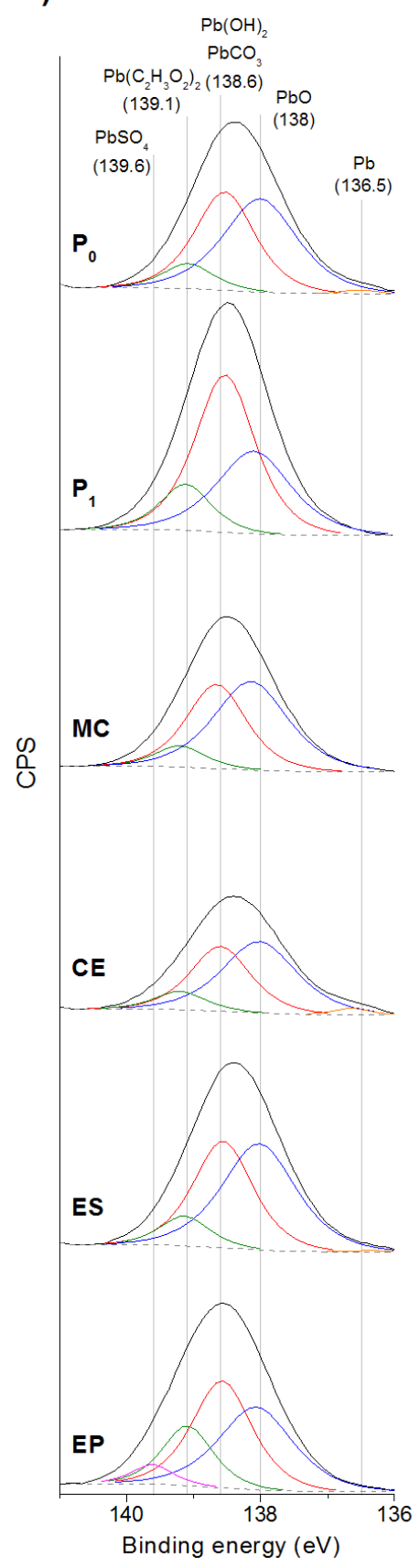

b) $\mathbf{O} 1 \mathrm{~s}$ Pbso,

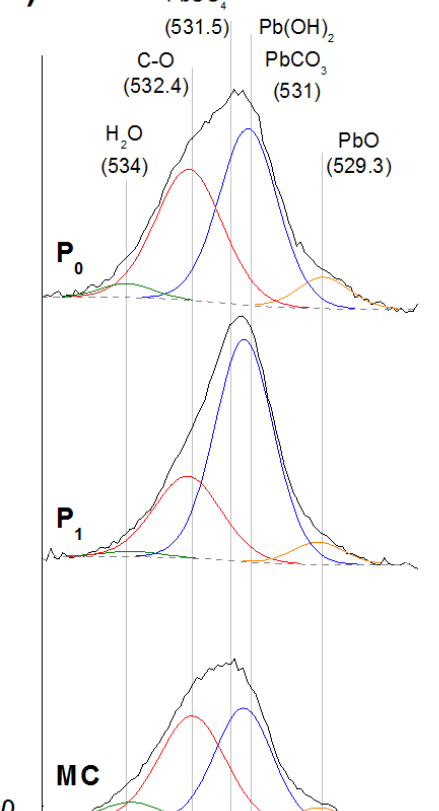

$\frac{\infty}{0}$

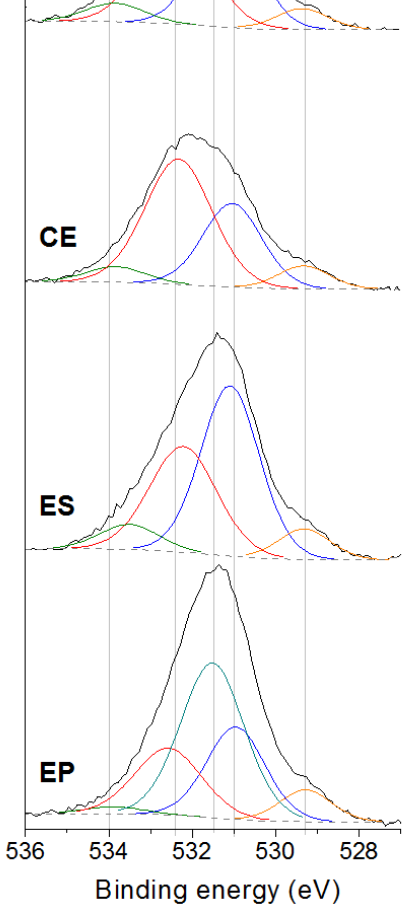

c) C $1 \mathrm{~s}$

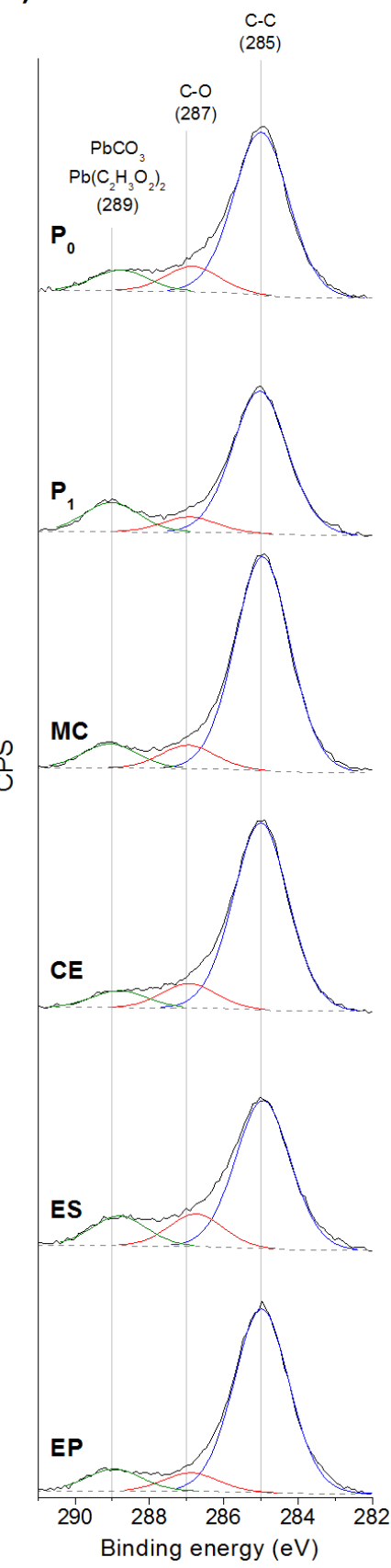

Fig. 9. High resolution XPS spectra of the lead coupons before alteration $\left(P_{0}\right)$, after alteration $\left(P_{1}\right)$, and after the alteration-treatment cycles: a) $\mathrm{Pb} 4 \mathrm{f}, \mathrm{b}) \mathrm{O}$ 1s, c) C $1 \mathrm{~s}$.

The XPS spectrum of the unaltered coupon $\left(\mathrm{P}_{0}\right)$ showed the peaks of lead oxide and hydroxide due to the fast passivation of lead in environmental conditions (Fig. 9 a). The presence of metallic lead $\left(\mathrm{Pb}^{0}\right)$ was not significant because of the low penetration of the $X$-ray beam (1-2 nm). Similar results were observed in the $O 1$ spectrum, in which the peaks of $\mathrm{Pb}(\mathrm{OH})_{2}$, C-O bonds and $\mathrm{PbO}$ were the most intense ones (Fig. 9 b). Water adsorbed on the surface was also detected. The most important peak in the $C 1 \mathrm{~s}$ spectrum was attributed to the C-C bond at $285 \mathrm{eV}$ (Fig. $9 \mathrm{c}$ ). This peak was due to the 
adventitious carbon, which is a thin layer of short chain hydrocarbons usual in the samples exposed to air. This peak is used normally for spectra calibration [38].

After the exposure to the atmosphere polluted with acetic acid, the peaks related with $\mathrm{PbCO}_{3}$ and $\mathrm{Pb}(\mathrm{OH})_{2}(\mathrm{~Pb} 4 \mathrm{f}$ at $138.6 \mathrm{eV}, \mathrm{O}$ 1s at $531 \mathrm{eV}$ and $\mathrm{C}$ 1s at $289 \mathrm{eV})$ showed an increase in their intensity (Fig. $9 \mathrm{a}, \mathrm{b}$ and c); in special in the peak of the oxygen because carbonates has three atoms of oxygen for each carbon or lead atom. These compounds were also observed by XRD (Fig. 2, section 3.2.). The peaks related with $\mathrm{Pb}\left(\mathrm{CH}_{3} \mathrm{CO}_{2}\right)_{2}$ experienced also a small increase in the intensity, however it was not identified by XRD due to its low crystallinity.

The intensity of the peaks of $\mathrm{PbCO}_{3}$ diminished in the spectra after the treatments, however the peaks still appear because they are overlapped with the peaks of $\mathrm{Pb}(\mathrm{OH})_{2}$ (Fig. $9 \mathrm{a}, \mathrm{b}$ and c). The mechanical cleaning induced also the decrease of the peaks of $\mathrm{PbO}$ in the $\mathrm{O} 1 \mathrm{~s}$ spectrum $(529.3 \mathrm{eV})$, because the abrasion removes all compounds from the surface. The presence of the peak of calcium demonstrated that residues of $\mathrm{CaCO}_{3}$, from the cleaning suspension, remained on the surface (Fig. $10 \mathrm{a}$ ).
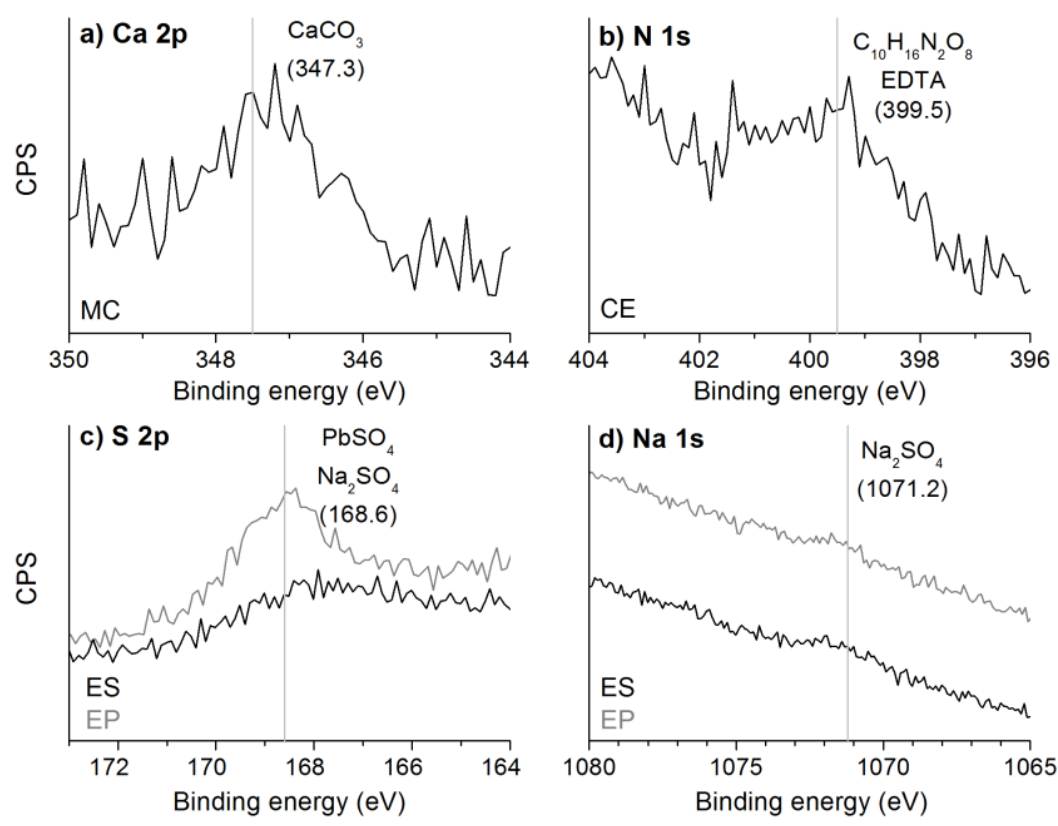

Fig. 10. High resolution XPS spectra on lead coupons after the alteration-treatment cycles: a) Ca 2p, b) $\mathrm{N}$ 1s, c) S 2p, d) Na 1s.

The chemical cleaning with EDTA induced a significant decrease in the intensity of the $\mathrm{PbCO}_{3}$ (and/or $\mathrm{Pb}(\mathrm{OH})_{2}$ ) in the $\mathrm{O}$ 1s spectrum (Fig. 9 b), even lower than the original coupon $\left(\mathrm{P}_{0}\right)$. This important decrease was related with the great affinity of the chelant agent for the lead carbonate and other corrosion products [19, 24]. The peaks related with the $\mathrm{Pb}\left(\mathrm{CH}_{3} \mathrm{CO}_{2}\right)_{2}$ also decreased and appeared the peak of the metallic lead (Fig. 9 a), showing that the thickness of the alteration layer was very low. However, the peak 
related to $\mathrm{PbO}$ in the $\mathrm{O} 1 \mathrm{~s}$ spectrum $(529.3 \mathrm{eV})$ maintained its intensity because the EDTA cannot chelate the lead of this compound [19]. An increase in the $\mathrm{OH}^{-}$peak (Fig. $9 \mathrm{~b})$ and the presence of amine groups $\left(\mathrm{N}\left(\mathrm{CH}_{3}\right)_{3}\right)$ in the $\mathrm{N} 1 \mathrm{~s}$ spectrum were also observed (Fig. 10 b), which were related with remains of EDTA adsorbed in the surface of the coupon.

The spectra of the coupon after the potentiostatic reduction (ES) showed a distribution of the bands similar to the unaltered lead for the $\mathrm{Pb} 4 \mathrm{f}$ spectrum with a slightly increase of the peak at $531 \mathrm{eV}$ in the $\mathrm{O}$ 1s spectrum (Fig. $9 \mathrm{a}$ and b). The electrochemical treatments produced the reduction of the carbonates to metallic lead, and it reacts quickly with the environment forming lead oxides and hydroxides (Fig. $6 \mathrm{c}$ ). In the case of the reduction and passivation treatment (EP), the formation of $\mathrm{PbSO}_{4}$ was detected by XPS ( $\mathrm{Pb} 4 \mathrm{f}$ at $139.6 \mathrm{eV}, \mathrm{O} 1 \mathrm{~s}$ at $531.5 \mathrm{eV}$ and $\mathrm{S} 2 \mathrm{p}$ at $168.6 \mathrm{eV}$ ) (Fig. $9 \mathrm{a}$, b and Fig. $10 \mathrm{c}$ ), and the crystals were observed by SEM (Fig. 6 d). In both electrochemical treatments, remains of sodium ( $\mathrm{Na} 1 \mathrm{~s}$ at $1071.2 \mathrm{eV}$ ) from the electrolyte, $\mathrm{Na}_{2} \mathrm{SO}_{4}$, were detected (Fig. $10 \mathrm{~d}$ ).

\section{Discussion}

This study has been focused on the assessment and comparison of the most common conservation treatments applied to historical lead. According to the survey carried out at the beginning of this study, mechanical cleanings are the most conventional ones, mainly the abrasion with a $\mathrm{CaCO}_{3}$ suspension. Regarding the chemical procedures, cleaning with the chelating agent EDTA was the principal one. And the most applied electrochemical treatment is the electrolytic reduction in $\mathrm{Na}_{2} \mathrm{SO}_{4}$. In this study the assessment of these three conservation procedures together with the potentiostatic reduction and subsequent passivation in $\mathrm{Na}_{2} \mathrm{SO}_{4}$ has been carried out by repetitive alteration-treatment cycles.

Examination of the lead coupons after each cycle showed that all the procedures induced different chemical and physical changes. These changes are summarized in the Table 3.

Table 3. Summary of the results obtained after six alteration-treatment cycles on lead.

\begin{tabular}{|c|c|c|c|c|c|c|}
\hline $\begin{array}{l}\text { Conservation } \\
\text { treatment }\end{array}$ & $\begin{array}{l}\text { Mass } \\
\text { variation }\end{array}$ & $\begin{array}{l}\text { Color } \\
\text { variation }\end{array}$ & $\begin{array}{l}\text { Gloss } \\
\text { variation }\end{array}$ & $\begin{array}{l}\text { Re- } \\
\text { alteration }\end{array}$ & Microstructure & $\begin{array}{l}\text { Chemical } \\
\text { changes }\end{array}$ \\
\hline$M$ & High & Moderate & Low & Fast & Polished & Low \\
\hline CE & Moderate & Low & Moderate & Fast & Heterogeneous & Moderate \\
\hline ES & Low & High & High & Slow & $\begin{array}{l}\text { Crystalline } \\
\text { deposits }\end{array}$ & Low \\
\hline EP & Low & High & High & Slow & $\begin{array}{l}\text { Crystalline } \\
\text { deposits }\end{array}$ & High \\
\hline
\end{tabular}


Mechanical cleaning with $\mathrm{CaCO}_{3}$ produced an important mass loss which depended on the intensity applied by the conservator. Gravimetrically, these coupons experienced a high re-alteration process because the abrasion left an extremely active surface. It also favored the appearance of the original metallic gloss although it left occasional scratches on the surface due to the grain size and hardness of the abrasive. The chemical composition of the surface after several cycles of alteration-treatment showed the decrease of the intensity in the peaks associated to lead carbonate and lead oxide in comparison with the altered coupon, however remains of the cleaning products were also detected in the surface, probably entrapped in the scratches.

The chemical cleaning with EDTA induced a moderate mass loss and a completely heterogeneous etched surface due to the chelation of the lead ions. The color and gloss of the treated coupons were the most similar to the original lead because the EDTA removed the lead carbonates and hydroxides which altered the color and gloss. The removal of the corrosion products was confirmed by XPS. The remains of EDTA adsorbed to the surface could contribute to decrease the natural passivation rate. Colorimetrically, the sample showed the most intense re-alteration, although gravimetrically it gained half of the mass than in the mechanical cleaning.

The electrochemical procedures induced a negligible mass loss because the lead of the corrosion products was converted back into metallic lead. Nevertheless, the recrystallization favored the increase of the roughness after each alteration-treatment cycle. The coupons treated by electrochemical reduction and passivation presented a homogeneous surface because the growth of $\mathrm{PbSO}_{4}$ crystals inside the holes favored the flattening of the surface. The re-crystallization induced a progressive color change to a bluish hue and a total loss of gloss, although the re-alteration rate decreased. The sample treated by potentiostaic reduction showed a chemical composition similar to the original coupon, however with a higher content of $\mathrm{Pb}(\mathrm{OH})_{2}$ due to the fast reaction of the metallic surface with the environment. On the contrary, the controlled passivation formed a surface layer of $\mathrm{PbSO}_{4}$.

\section{Conclusions}

The assessment and comparison of common conservation treatments applied to tarnished lead showed that all of them induced chemical and/or physical changes on the lead surface. Abrasion with a $\mathrm{CaCO}_{3}$ suspension favored the appearance of the metallic gloss although it produced an important mass loss with occasional scratches on the 
surface in which remains of the cleaning products were entrapped. The chemical cleaning with EDTA removed the lead carbonates and hydroxides leaving the original color of the lead, however it etched the surface inducing a moderate mass loss and a fast re-alteration process. The electrochemical procedures induced a negligible mass loss, however the roughness and surface color progressively changed to a bluish hue.

None of the conservation treatments studied outperforms the others in all tests, so the selection of the most appropriate procedure should be carried out by the conservatorrestorer depending on the preference given to the different aspects. In most cases, a combination of them (for instance, an electrochemical treatment to reduce the corrosion products followed by a slight mechanical polish to recover initial aspect) will allow to make the most of the advantages and minimize the disadvantages of each procedure that have been demonstrated in this study.

\section{Acknowledgements}

The authors kindly thank B. Ramirez Barat, I. Llorente and J.M. Vélix (CENIM-CSIC, Madrid) for their help during the treatments, to C. Vazquez Calvo (IGEO-CSIC-UCM, Madrid) for the rugosimetry measures and to all professionals who answered the survey. This work has been partially funded by CREMELII Project Ref. HAR2014-54893-R, GEOMATERIALES 2-CM Program Ref. S2013/MIT-2914 and the Fundação do Ministério de Ciência e Tecnologia de Portugal (Post-doctoral grant ref. SFRH/BPD/108403/2015). Professional support from TechnoHeritage (Network on Science and Technology for the Conservation of Cultural Heritage) is also acknowledged.

\section{References}

[1] L. Selwyn, Metals and corrosion: a handbook for the conservation professional, Canadian Conservation Institute, Canada, 2004.

[2] V. Costa, F. Urban, Lead and its alloys: metallurgy, deterioration and conservation, Studies in Conservation, 50 (2005) 48-62.

[3] C. Renfrew, Cycladic Metallurgy and the Aegean Early Bronze Age, American Journal of Archaeology, 71 (1967) 1-20.

[4] A. Niklasson, L.-G. Johansson, J.-E. Svensson, Influence of acetic acid vapor on the atmospheric corrosion of lead, Journal of the Electrochemical Society, 152 (2005) B519B525.

[5] A. Niklasson, L.-G. Johansson, J.-E. Svensson, The influence of relative humidity and temperature on the acetic acid vapour-induced atmospheric corrosion of lead, Corrosion Science, 50 (2008) 3031-3037.

[6] J. Tétreault, J. Sirois, E. Stamatopoulou, Studies of lead corrosion in acetic acid environments, Studies in conservation, 43 (1998) 17-32. 
[7] S.S. Abd-El Rehim, N.H. Amin, L.I. Ali, N.F. Mohamed, Electrochemical behaviour and corrosion of lead in some carboxylic acid solutions, Journal of Chemical Technology \& Biotechnology, 72 (1998) 197-201.

[8] P. Taylor, V.J. Lopata, Stability and solubility relationships between some solids in the system $\mathrm{PbO}-\mathrm{CO}_{2}-\mathrm{H}_{2} \mathrm{O}$, Canadian Journal of Chemistry, 62 (1984) 395-402.

[9] J. Tétreault, E. Cano, M. van Bommel, D. Scott, M. Dennis, M.-G. Barthés-Labrousse, L. Minel, L. Robbiola, Corrosion of copper and lead by formaldehyde, formic and acetic acid vapours, Studies in conservation, 48 (2003) 237-250.

[10] A. Niklasson, L.-G. Johansson, J.-E. Svensson, Atmospheric corrosion of lead the influence of formic acid and acetic acid vapors, Journal of the Electrochemical Society, 154 (2007) C618-C625.

[11] A.V. Echavarría, F.E. Echeverría, C. Arroyave, E. Cano, J.M. Bastidas, Carboxilic acids in the atmosphere and their effect on the degradation of metals, Reviews on coatings and corrosion, 21 (2003) 395-413.

[12] D. Lafuente, E. Cano, I. Llorente, A. Crespo, J. Künne, A. Schieweck, The effects of organic pollutants on metals in museums: Corrosion products, synergistic effects and the influence of climatic parameters, in: Metal 2013. Triennial conference of the International Council of Museums Committee for Conservation Metal Working Group (ICOM-CC Metal WG), 16 ${ }^{\text {th }}-20^{\text {th }}$ September 2013, Edinburgh, Scotland, 2013.

[13] L.T. Gibson, C.M. Watt, Acetic and formic acids emitted from wood samples and their effect on selected materials in museum environments, Corrosion Science, 52 (2010) 172-178.

[14] D. Thickett, L.R. Lee, Selection of materials for the storage or display of museum objects, The British Museum Ocasional Paper, (2004).

[15] C. Chiavari, C. Martini, D. Prandstraller, A. Niklasson, L.-G. Johansson, J.-E. Svensson, A. Åslund, C.J. Bergsten, Atmospheric corrosion of historical organ pipes: the influence of environment and materials, Corrosion Science, 50 (2008) 2444-2455.

[16] A. Niklasson, S. Langer, K. Arrhenius, L. Rosell, C.J. Bergsten, L.-G. Johansson, J.E. Svensson, Air pollutant concentrations and atmospheric corrosion of organ pipes in European church environments, Studies in Conservation, 53 (2008) 24-40.

[17] R. Edwards, W. Bordass, D. Farrell, Determination of acetic and formic acid in lead corrosion products by ion-exchange chromatography, Analyst, 122 (1997) 1517-1520.

[18] J.M. Cronyn, Elements of archaeological conservation, Routledge, London and New york, 2003.

[19] B. Schotte, A. Adriaens, Treatments of corroded lead artefacts: An overview, Studies in Conservation, 51 (2006) 297-304.

[20] D.R. Lide, CRC Handbook of Chemistry and Physics, Internet Version 2005, http://www.hbcpnetbase.com, CRC Press, Boca Raton, FL, 2005.

[21] L.S. Selwyn, Historical silver: Storage, display, and tarnish removal, Journal of International Institute for Conservation of Historic and Artistic Works, 15 (1990) 12-22.

[22] E.R. Caley, Coatings and incrustations on lead objects from the Agora and the method used for their removal, Studies in Conservation, 2 (1955) 49-54.

[23] J. Watson, Conservation of lead and lead alloys using EDTA. solutions, in: Lead and Tin Studies in Conservation and Technology, UKIC Occasional Paper No 3, United Kingdom Institute for Conservation, London, 1985, pp. 44-45.

[24] C.E. Adams, A comparison of three chelating agents for the treatment of corroded lead. Master of Art Conservation. Research Report 114 Queen's University (Kingston Ont.), 1987.

[25] C. Degrigny, Use of electrochemical techniques for the conservation of metal artefacts: a review, Journal of Solid State Electrochemistry, 14 (2009) 353-361.

[26] H.J. Plenderleith, A.E.A. Werner, The conservation of antiquities and works of art: treatment, repair and restoration, Oxford University Press, 1971.

[27] E.M. Nosek, The investigation and conservation of a lead paten from the eleventh century, Studies in Conservation, 30 (1985) 19-22. 
[28] I.A. Carradice, S.A. Campbell, The conservation of lead communion tokens by potentiost atic reduction, Studies in Conservation, 39 (1994) 100-106.

[29] C. Degrigny, R. Le Gall, Conservation of ancient lead artifacts corroded in organic acid environments: Electrolytic stabilization/consolidation, Studies in Conservation, 44 (1999) 157-169.

[30] J. Barrio, M. Arroyo, E. Cano, J.M. Bastidas, A.I. Pardo, Investigación sobre el proceso de estabilización y limpieza por reducción potenciostática de un plomo epigráfico romano, in: Investigación en conservación y restauración : II Congreso del Grupo Español del IIC : [9, 10 y 11 de noviembre de 2005, Barcelona], Museu Nacional d'Art de Catalunya, Barceona, 2005.

[31] B. Schotte, A. Adriaens, F. Dhooghe, D. Depla, M. Dierick, M. Dowsett, E. Lehmann, P. Vontobel, Chemical and morphological changes of historical lead objects as a result of the use of electrolytic reduction as a stabilization treatment, Analytical Chemistry, 78 (2006) 8319-8323.

[32] ASTM D1729, Standard practice for visual appraisal of colors and color differences of diffusely-illuminated opaque materials, in, 2009.

[33] D. Malacara, Color vision and colorimetry: Theory and applications, SPIE Press, Bellingham, 2002.

[34] K. Minolta, Precise color communication: color control from perception to instrumentation, Konica Minolta Sensing INC., 2007

[35] C. Wagner, L. Davis, M. Zeller, J. Taylor, R. Raymond, L. Gale, Empirical atomic sensitivity factors for quantitative analysis by electron spectroscopy for chemical analysis, Surf Interface Anal, 3 (1981) 211-225.

[36] Measurement Services Division of the National Institute of Standards and Technology (NIST), NIST X-ray Photoelectron Spectroscopy Database 20, Version 4.1, in, 2012.

[37] T. Palomar, B. Ramírez Barat, E. García, E. Cano, A comparative study of cleaning methods for tarnished silver, Journal of Cultural Heritage, 17 (2016) 20-26.

[38] T.L. Barr, S. Seal, Nature of the use of adventitious carbon as a binding energy standard, Journal of Vacuum Science \& Technology A, 13 (1995) 1239-1246. 